\title{
PROCESSOS EDUCATIVOS: A DISGRAFIA VERSUS FRACASSO ESCOLAR
}

\author{
Sebastiana Maria Ribeiro da Silva ${ }^{1}$ \\ Elisângela Maura Catarino
}

\footnotetext{
${ }^{1}$ Secretaria Municipal de Educação de Serrinha (SMES) Serrinha, BA, Brasil.

${ }^{2}$ Centro Universitário de Mineiros (UNIFIMES), Mineiros, Brasil.
}

\begin{abstract}
Resumo: Este artigo aborda o assunto disgrafia, alteração da escrita normalmente ligada a problemas perceptivo- motores, porém não associada a nenhum tipo de comprometimento intelectual, e vem abrir um debate sobre essa dificuldade de aprendizado da escrita, com intuito de buscar conhecimentos aprofundados para que a disgrafia seja vista como um problema solucionável, e, quando envolvidas escola e família, venham ajudar o aluno a amenizar essa angústia. A letra ilegível pode ser apenas uma incapacidade de recordar a grafia das letras, necessitando assim de estimulação linguística e atendimento individualizado.
\end{abstract}

Palavras-chave: Disgrafia. Dificuldades. Psicomotricidade. Escrita.

Como citar: SILVA, S. M. R; CATARINO, E. M. Processos Educativos: a disgrafia versus fracasso escolar . Revista Científica Novas Configurações - Diálogos Plurais, Luziânia, v. 1, n.1, p. 46- 51, 2020. https://doi.org/.10.4322/2675-4177.2020.006

\section{INTRODUÇÃO}

É indiscutível o papel preponderante que a escola representa na vida do educando, pois nela o mesmo apreende e desvenda através da leitura e da escrita realidades inéditas. É essencial que descubra durante a escolaridade que a escrita é uma prática social imbuída de mecanismos socioculturais. Muitos alunos apresentam dificuldades enormes para realizar qualquer tarefa que exija habilidades básicas de escrita. É comum observar, principalmente em alunos de séries iniciais muitas incorreções na escrita, e escrever transforma-se em motivo de insatisfação. A Disgrafia é a escrita feia, normalmente ligada a problemas perceptivo-motores.

Nessa direção Zorzi (1998), salienta que:

Entendendo melhor a complexidade da própria escrita e todos os desafios que ela impõe a quem deseja dela se apropriar, o educador pode compreender de maneira mais adequada a escrita que as crianças produzem e, assim, valorizá-las porque podem estar denotando um grande esforço de compreensão. (ZORZI, 1998, p.108).

Diante o exposto, percebe-se que o desenvolvimento da escrita merece muita atenção por parte do professor, pois essa dificuldade não pode passar despercebida. São muitos os fatores que podem ocasioná-la. Segundo alguns autores pode estar relacionada à psicomotricidade e envolve as habilidades de coordenação geral, coordenação motora, motricidade ampla e especialmente fina. Para ler é necessário que se escreva corretamente, é preciso que o leitor seja conduzido pela escrita para que esse processo se

Apoio financeiro: Nenhum.

Conflitos de interesses: Os autores declaram não haver nenhum conflito de interesse.

Correspondência: sebastiana_100@hotmail.com

Recebido: 02 Abr 2020.

Aprovado: 17 Mai 2020

Editor: Marcelo Máximo Purificação.

Este é um artigo publicado em acesso aberto (Open Access) sob a licença Creative Commons Attribution, que permite uso, distribuição e reprodução em qualquer meio, sem restrições desde que o trabalho original seja corretamente citado. 
torne prazeroso. A escrita é uma das formas de comunicação entre homens e não pode ser vista como uma mera representação de letras e palavras.

É importante salientar que a letra "feia" que algumas crianças conseguem transcrever vai muito além do que a escola e a família consideram como preguiça ou desinteresse, e a escola deve ocupar a posição privilegiada de mediadora da interação da criança com a escrita; compreender que as crianças constroem conhecimento e também aprimoram novos conhecimentos a respeito do que é a escrita: sua natureza, seus usos e funções. Desenvolve habilidades importantes, úteis não só na escola, mas na própria vida.

\title{
2 DESENVOLVIMENTO
}

A escrita está ligada diretamente ao desenvolvimento das atividades escolares, de forma que de $30 \%$ à $60 \%$ das atividades realizadas em sala de aula envolvem o desenvolvimento da escrita. A escrita, portanto, representa uma das formas pela qual é desempenhado o papel de difundir a cultura e os conceitos da humanidade, sendo esta uma forma de comunicação considerada sodisticada e de alto grau de refinamento (CARDOSO; CAPELLINI, 2016). Para os autores o desenvolvimento de uma forma tão fundamental de comunicação para a humidade envolve alguns aspectos importantes, são eles:

[...]controle motor fino, integração viso-motora, planejamento motor, propriocepção, percepção visual, atenção sustentada e consciência sensorial dos dedos, e que, alterações em uma ou mais dessas funções podem ocasionar falhas no desenvolvimento da habilidade escrita. (CARDOSO; CAPELLINI, p.4, 2016)

O desenvolvimento da escrita ocorrida no espaço escolar não representa um processo linear, sendo este experimentado de formas e tempos distintas por cada aluno, não sendo este processo linear é comum que alguns alunos apresentem dificuldades na aprendizagem da caligrafia e este obstáculo interfere na produção de uma escrita legível denomina-se disgrafia.

A disgrafia é conhecida por muitos como um distúrbio da aprendizagem da escrita que afeta as crianças. É preciso saber trabalhar com o conflito, perceber a situação e atuar. Na maioria das vezes os alunos são tratados como iguais, onde são condicionados a ler e a escrever. No entanto, é necessário que cada criança veja na escrita um trabalho que não lhe transmita bloqueio ou até mesmo cansaço.

Sobre isso Ferreiro, (1991) salienta que:

\begin{abstract}
Porém, atribuir as deficiências do método à incapacidade da criança é negar que toda a aprendizagem supõe um processo, é ver déficit ali onde somente existem diferenças em relação ao momento de desenvolvimento conceitual em que se situam. (FERREIRO, 1991, p. 277).
\end{abstract}

É comum chamar o aluno que não consegue escrever de preguiçoso, levando-o a sentir-se desmotivado. Geralmente, alunos disgráficos apresentam problemas emocionais e tendem a sofrer em função de seu mau rendimento escolar e diante de seus repetidos fracassos tornam-se deprimidos e sentem-se excluídos. Em algumas situações a família prefere aceitar o fracasso escolar dos seus filhos à entender que pode ser uma dificuldade que a criança apresente relacionado a um distúrbio no desenvolvimento da escrita, que envolve o afetivo e o emocional, portanto faz-se necessário o apoio dos pais para que a criança não se sinta inferiorizada diante dos outras, evitando assim o desgaste no seu desenvolvimento acadêmico e emocional e de suas relações.

Situações que ocorrem este desgaste são ligados, muitas vezes, a falta de respeito ao desenvolvimento psicomotor, do meio social e até mesmo idade dos alunos, que são cobrados a cumprir exercícios de leitura e escrita sem que sejam perguntados sobre o que realmente representam para eles; ou seja, a escola fornece um currículo pronto que deve ser utilizado não sinalizando as necessidades dos alunos.

Refletindo sobre as diretrizes curriculares em vigor no Brasil, é possível dizer que:

Pensar em adequação "o curricular significa considerar o cotidiano das escolas, levando-se em conta as necessidades e capacidades dos seus alunos e os valores que orientam a prática pedagógica. Para os alunos que apresentam necessidades educacionais especiais essas questões têm um significado particularmente importante”. (BRASIL, 2003, p. 33) 
Diante disto, é preciso frisar a importância da adequação do currículo como sendo um elemento dinâmico da educação, visando os alunos com necessidades educacionais especiais através da flexibilização, na prática educacional, com o objetivo de atender todos os discentes.

É preciso compreender que todo indivíduo em processo de construção da escrita necessita de cuidados especiais, pois muitas são as dificuldades no traçado das letras, no espaço, na leitura, etc. A criança com essa dificuldade sofre muito por não conseguir uma escrita que ela própria consegue decifrar depois, e começa a ficar refém desse sofrimento. Não lê o que escreveu e ainda mais, não obtém a ajuda necessária por parte da escola.

Para Jesus (2013),

A escola deve propiciar melhores condições de aprendizagem, selecionando atividades e posturas necessárias, que promovam o resgate da auto-estima do aluno. $\mathrm{O}$ aspecto afetivo tem uma profunda influência sobre o desenvolvimento intelectual. Ele pode acelerar ou diminuir o ritmo de desenvolvimento, e determinar sobre que conteúdos a atividade intelectual se concentrará e, na teoria de Piaget, o desenvolvimento intelectual é considerado como tendo dois componentes: um cognitivo e outro afetivo que, desenvolvem-se paralelamente. Afeto inclui sentimentos, interesses, desejos, tendências, valores e emoções em geral. (JESUS, 2013, p.20)

Neste aspecto a afetividade tem fator relevante na construção do conhecimento, não apenas o afeto voltado para o outro, mas também o afeto voltado para si mesmo, de forma que o aluno deve se sentir acolhido pela escola pois a construção de si perpassa também pela forma como o meio se configura e reconfigura o indivíduo, havendo assim uma troca de construção entre sujeito- meio sujeito. No cenário escolar esses sujeitos podem se rejeitar e se anular, assim como pode enfrentar, abster-se ou construir a partir de algo que seja da sua singularidade

Nesse contexto a psicomotricidade, pode ser uma aliada. Psicomotricidade é o estudo dos problemas motores; e a educação psicomotora é necessária na escola. Desde os primeiros dias deve ser levada à prática de exercícios que envolvam análise, lógica, relações entre números, com o objetivo de fazer com que adquira uma noção do corpo e espaço. "E, já que as ações de ler e de escrever estão ligadas ao espaço e ao tempo, os exercícios de organização do espaço e do ritmo contribuem para a escrita e a leitura". (AJURIAGUERRA, 1990, p. 128).

Como uma importante contribuição da psicomotricidade podemos citar que ela,

Estimula o desenvolvimento psicomotor nas crianças gera a construção de uma consciência dos movimentos corporais integrados com sua emoção e expressos por esses movimentos. Neste reconhecimento do mundo, o sujeito torna-se consciente de si, tendo condições de diferenciar-se. (DANTAS, L. M. PINTO, E. C. B. p.3)

A educação psicomotora deve ser vista como técnicas e que, quando utilizadas, levam a criança a adquirir noção de motricidade e afetividade. Os movimentos que envolvem o corpo são de suma importância para desenvolver a afetividade e a personalidade.

Escrever não envolve apenas habilidade cognitiva e motora, não se escreve apenas só por escrever, mas envolve emoções. Brincar, correr, cair são atividades que trabalham o corpo e ajudam a desenvolver o sistema psicomotor diminuindo a ansiedade. Os antigos já sabiam a importância do brincar para o desenvolvimento integral do homem. Eles sabiam que exercitar a mente, o corpo e a alma favoreciam o desenvolvimento físico e o intelectual.

Atividades lúdicas que envolvam a lateralidade levam a criança por meio de exercícios simétricos, a incentivar a descoberta de seu lado dominante e estabelecer um equilíbrio de força e de destreza entre os dois lados. São atividades simples, porém de grande importância na superação da disgrafia.

Aqui intervêm os diferentes fatores classicamente invocados; "atraso da linguagem, perturbações especiais e, sobretudo temporais distúrbios gnósticos e práxicos, dislateralidade, antecedentes hereditários entre os parentes ascendentes ou colaterais, etc. Todos esses elementos obrigam a criança a um esforço suplementar para compensar seus déficits ou conseguir uma integração, apesar de sua persistência". (AJURIAGUERRA, 1990, p. 77).

Trabalhar o espaço e o tempo também são interessantes, pois ajudam a desenvolver a organização e a ter noção de obliquidade e trajeto. Podem ser praticadas brincadeiras simples, mas dinâmicas que vão induzir ao domínio da escrita.

Dessa forma, a atividade lúdica deve estar presente em todas as práticas pedagógicas no sentido de enriquecer e ampliar o universo físico, social e cognitivo da criança. 
Quando a escola não exerce seu papel de mediadora, a escrita pode permanecer totalmente distante. A escola é responsável pelo encontro da criança com a escrita e nunca deve ser o lugar onde as atividades desenvolvidas pelas crianças já cheguem prontas. Não pode ser um meio onde tudo é pensado, organizado e gerido pelos adultos.

Na linha dessas ideias Bulgraen, (2009), estabelece que:

[...]devemos considerar as experiências sociais acumuladas de cada aluno e seu contexto social, de modo a construir a partir daí um ambiente escolar acolhedor em que o aluno se sinta parte do todo e esteja totalmente aberto a novas aprendizagens. (BULGRAEN, 2009, p. 4)

É corriqueiro ver o professor cobrar de forma única que seus educandos aprendam desde as primeiras séries a rabiscar ou até mesmo ler sem se preocupar com as dificuldades apresentadas por cada uma delas. Esquece-se que o verdadeiro papel da escola deve ser de promover um espaço onde a criança possa experimentar como uma um ambiente prazeroso e onde a escrita também faça parte de seu mundo.

Torna-se uma prática constante no ensino-aprendizagem exigir dos alunos a leitura e a escrita quase perfeitas, da mesma forma que pais cobram da escola o ensino sem que seus filhos sejam ouvidos a respeito de suas dificuldades, angústias e anseios, que esse processo possa ocasionar. A escola e a família devem ser parceiras e juntos oferecer o apoio necessário para a criança sentir-se protegida e segura diante das suas dificuldades.

Para Kaufman (1994),

\begin{abstract}
Situações desse tipo são as que, em determinados momentos, podem ser úteis para colocar em cheque construções intelectuais que devem ser superadas. Isso, por certo, exigirá enormes esforços e provocará, em muitos casos, fortes resistências. Porém a aprendizagem não consiste de uma mera soma de conhecimentos, mas de complexas reestruturações, e se dá a partir de situações problemáticas que devem ser resolvidas. (KAUFMAN, 1994, p. 102).
\end{abstract}

Muitos professores sentem-se despreparados para lidar com a situação, por encontrarem salas superlotadas ou multisseriadas e acabam isolando esses alunos. Aplicam métodos inadequados que não condizem com a realidade do educando, levando-o ao desequilíbrio e tornando o ambiente escolar pobre de estímulos, não favorecendo a aprendizagem.

"Diminuição do número nas classes e formação coerente e prolongada dos professores, são os dois fatores em que se pensa de imediato ao falar em terminar com o atraso escolar". (AJURIAGUERRA, 1990, p. 137).

Ensinar não é mera transmissão de conhecimentos, é estimular o aluno a criar novos hábitos e a aprendizagem da escrita deve ser entendida como um processo de ser social ativo, considerando suas experiências e interações, a fim de que ele possa construir a escrita. É importante ressaltar que não ensinamos uma criança a escrever é ela quem ensina a si mesma, com a nossa ajuda e a de seus pais. Cada criança possui seu caminho próprio e é preciso que ela viva situações de aprendizagem que lhe permitam construir sua própria competência.

\title{
CONSIDERAÇÕES FINAIS
}

A grande realidade enfrentada pelas escolas no Brasil é alarmante; salas superlotadas, multisseriadas, professores insatisfeitos por não receberem o apoio necessário para exercerem o seu trabalho. No entanto, o aluno não pode ser refém de todos esses problemas que afetam a educação do país.

Alunos disgráficos estão presentes no cotidiano escolar e precisam ser ajudados de forma que se sintam protegidos e à vontade; que a escola realmente cumpra o seu papel mediador no aprendizado da leitura e da escrita de maneira prazerosa; buscando subsídios para que essa dificuldade não seja vista como um problema sem solução. É preciso que a escola trabalhe de forma a incentivar cada vez mais o aluno a aprender e sentir-se sujeito desse processo.

Para ajudar a solucionar esse problema são necessárias atividades que envolvam o brincar e que ajudem a desenvolver a coordenação motora ampla, fina e direcionando a coordenação viso-motora, organização espacial buscando sempre envolver a família para que esse processo seja estendido a sua casa. A escola deve sim, ser um meio de vida em que o aluno possa opinar, discutir e criar condições favoráveis a todo e qualquer aprendizado.

Cabe ao educador respeitar as limitações apresentadas por cada aluno; sinalizar possíveis transtornos e trabalhar um currículo voltado para a realidade em que os alunos não sejam vistos com um 
grau de intelectualidade comum a todos. Uma educação para a vida real, em que as diferenças são a regra e não a exceção; escutar o aluno, encaminhá-lo ao psicopedagogo, ao psicólogo ou outros profissionais. O aluno deve sentir-se protegido e ver na escola um espaço de construção do saber sem traumas e exclusões. Tomando de empréstimo da fala de Santos apud Candau (2016) "temos o direito a ser iguais, sempre que a diferença nos inferioriza; temos o direito de ser diferentes sempre que a igualdade nos descaracteriza".

\section{REFERÊNCIAS}

ABREU, D. M. Psicomotricidade: desenvolvimento e dificuldades encontradas dentro da sala de aula na educação infantil. Acesso em: $<$ http://nippromove.hospedagemdesites.ws/anais_simposio/arquivos_up/documentos/artigos/1fe8f8519bc b434ccf74e620ed33aa4e.pdf>. Acesso: 13 de ago. 2019

BRASIL. Estratégias para a educação de alunos com necessidades educacionais especiais. coordenação geral: SEESP/MEC ; organização: Maria Salete Fábio Aranha. ñ Brasìlia : MinistĖrio da Educação, Secretaria de Educação Especial, 2003.

AJURIAGUERRA, J. de. A Dislexia em questão: dificuldades e fracassos na aprendizagem da língua escrita. Porto Alegre: Artes Médicas, 1984.

BRASIL. Secretaria de Educação Fundamental. Parâmetros Curriculares Nacionais. Língua Portuguesa. Brasília, 1997.

CONDEMARIN, Mabel. Dislexia: manual de Leitura Corretiva. Porto Alegre: Artes Médicas, 1986.

FERREIRO, Emília. Psicogênese da Língua Escrita. Porto Alegre: Artes Médicas, 1985.

KAUFMAN, Ana Maria. A Leitura e a escrita e a escola: uma experiência construtivista. Porto Alegre: Artes Médicas, 1994.

MEUR, A de. Psicomotricidade: educação e reeducação infantil. São Paulo: Manole, 1989.

ZORZI, Jaime Luiz. Aprender a Escrever. A apropriação do sistema Ortográfico. Porto Alegre: Artes Médicas, 1998.

JESUS, A. V. Relação professor/aluno na Educação Infantil. Artigo, 2013. Disponível em: <http://pedagogiaaopedaletra.com/relacao-professoraluno-na-educacao-infantil/>. Acesso em: 15 de ago. 2019.

DANTAS, L. M. PINTO, E. C. B. PSICOMOTRICIDADE E EDUCAÇÃO INCLUSIVA: VIVÊNCIAS EM SALA DE AULA. disponível https://educere.bruc.com.br/CD2013/pdf/10022 6266.pdf. Acesso em: 15 de ago. 2019.

$\begin{array}{lcccl}\text { BULGRAEN, V. C. O PAPEL DO PROFESSOR E SUA MEDIAÇÃO NOS PROCESSOS DE } \\ \text { ELABORAÇÃO } & \text { DO } & \text { CONHECIMENTO. } & \text { Disponível } & \text { em: }\end{array}$ http://www.conteudo.org.br/index.php/conteudo/article/viewFile/46/39. Acesso em: 15 de ago. 2019.

\section{Informações sobre os autores:}

SMRS: Mestranda em Intervenção Educativa e Social (MPIES) - UNEB/2019.1. Graduada no Curso Normal Superior pela Universidade do Norte do Paraná (UNOPAR) com Especialização em Psicopedagogia pela Faculdade do Noroeste de Minas- FINOM. Pertence ao Grupo de Pesquisa GEPERCS. Professora da Educação Básica na rede municipal de Serrinha- BA e Auxiliar Administrativo com a função de Técnica em Farmácia no Hospital Municipal de Serrinha/(SESAB).Email: sebastiana_100@hotmail.com 
EMC: Realizou Estágio Pós-doutoral em Educação pela Escola Superior de Educação de Coimbra ESEC/PT (2017-2019) sob a orientação da Dra ${ }^{a}$ Fátima Neves. Doutora em Ciências da Religião pela PUC-GO (2005 - CAPES 5) na Linha de Pesquisa Religião e Movimentos Sociais. Mestra em Teologia com especialização em Educação Comunitária Infância e Juventude pela EST/UFRGS (2010 - Conceito máximo na CAPES). Especialista em Língua Portuguesa pela Universidade Salgado de Oliveira (2007) e Docência do Ensino Superior pela FAMATEC (2012). Licenciada em Língua Portuguesa e inglesa e suas respectivas licenciaturas, pela Universidade Estadual de Goiás (2004) e Licenciada em Filosofia pelo Instituto de Ciências Sociais e Humanas - ICSH (2003). É servidora pública da Secretaria Estadual de Educação de Goiás - SEDUCE (1999 - Professora P-IV) e da Fundação Integrada Municipal de Ensino Superior (2015 - Professora Titular - CII), onde atua como professora na Pós-graduação e nos Cursos de Medicina Veterinária, Engenharia, Pedagogia, Educação Física e Psicologia. Coorientadora no Mestrado Profissional em Intervenção Educativa e Social - MPIES/UNEB. Colíder do Grupo de Pesquisa Psicologia, Processos Educativos e Inclusão da Universidade Federal do Mato Grosso do Sul (UFMS); Pesquisadora no Grupo de Pesquisa NEPEM/UNIFIMES/CNPq. Atualmente trabalha com as seguintes temáticas: Literatura. Linguagem. Educação e Diversidade e Educação Especial com foco nos surdos.

Contribuição dos autores: SMRS: conceitualização, captação de recursos, supervisão, redação. 